\title{
The Perlocutionary Effects of Cautionary Notices on Motoristusing Nigeria Highways
}

\author{
Opoola Bolanle Tajudeen \\ Federal University, OyeEkiti, Nigeria \\ Folorunso Emmanuel Awoniyi \\ Osun state University, Ikire Campus, Nigeria \\ Opoola Ayobami Fatimo \\ Federal College of Education (Special), Oyo, Nigeria \\ Olatunbosun Odusanya \\ Federal University, OyeEkiti, Nigeria
}

\begin{abstract}
The dangers associated with traffic violations on the highways cannot be overemphasized. This work, therefore, examines the communicative effectiveness of cautionary notices on Nigeria highways, where these cautionary notices are mostly found, by looking at the attitude of the motorists towards the cautionary notices and the attention people generally paid to them. This study, which is descriptive, drew its data from the major highways in Nigeria where these notices were erected by notable construction companies as well as other corporate bodies. The analyses of these notices were based on the performed acts of the speech act theory, as these notices, in the view of many, are not considered as ordinary graphics, writings and symbols because of their significance on both the writers and the readers. The study carefully examines how the intention of these cautionary notices is achieved in the communication between the dispatcher and recipient in order to determine the effectiveness of these notices on the behavior of the motorists. The work thus brings out the critical discourse elements of the subject matter. Findings reveal that some of the cautionary notices are regarded as warnings while some are viewed as a combination of warning and advice. The study further shows that the use of cautionary notices has helped in the maintenance of law and order on the highway especially among vehicle owners, making them to be security conscious and thus helping to eradicate preventable deaths through over speeding and sundry vices. Finally, the study reveals that the use of cautionary notices is a new dimension in the area of linguistic landscape and if the use is further encouraged, it would help to maintain peace, orderliness, and guide against fatal accidents on the highways.
\end{abstract}

Index Terms - cautionary notices, traffic violations, linguistic landscape, law and order, perlocutionary

\section{BACKGROUND}

Cautionary notices give or serve as a warning; admonitory. It serves series of functions. From available information, it appears that in most cases, these notices are effective for protecting intellectual property and also engender attitudinal change. Cautionary notices give notice to third parties that the subject matter referenced in the notice is crucial and germane. Or is a trademark of another and cautions third parties against unauthorized and reckless use lest they be charged with infringement or face adverse consequences.

The requirements for an effective cautionary notice vary from country to country, but there are basic requirements common to all. The notice should state the name and possibly, the address of the owner of the intellectual property or initiator of the message being communicated as well as the message itself in specific terms. Once the cautionary notice is published, however, it is assumed that third parties are aware of the messages being communicated and they are expected to pay attention to the messages.

Likened to high ways, cautionary notices are instrumental to the safety of road users. Historically, some of the first roadside signs — ancient milestones - merely gave distance measures. The early signs did not have high-contrast lettering and their messages might have been easily overlooked.

In Nigeria for instance, the notices inform, educate and advocate for a reserved driving manner. Examples of such are the traffic warning signs. Depending on the circumstances, the notices may indicate a hazard ahead on the road that may not be readily apparent to a driver. The notices are herein treated as linguistic landscape and therefore, subjected to analysis. This kind of adventure is technically within the scope of discourse analysis or critical discourse analysis, a subset of structural linguistic study.

In some cases, scholars talk about 'Critical Discourse Analysis', and 'Conversation Analysis' interchangeably. Either way, the focus of this field of study is the analysis of the language in use. The concept 'discourse' has been defined in 
different ways by different scholars. Some of these definitions are provided below: According to (Stubbs 1983), discourse is 'language above the sentence or above the clause. (Fasold 1990) sees discourse as the study of any aspect of language use.

Discourse analysis is an indispensable concept for understanding society and human responses. It is also central to understanding language itself. Discourse analysis examines how language, meaning and society interrelate. Critical Discourse Analysis (henceforth CDA) "is the uncovering of implicit ideologies in texts. It unveils the underlying ideological prejudices and therefore the exercise of power in texts" (Widdoson, 2000; 2007).

Compared with other branches of linguistics, discourse analysis is a new area of importance and it has gradually moved from mere description of sentences to a 'scientific' aspect of academic study. On their own part.(Brown and Yule 1998) observe that the analysis of discourse is, necessarily the analysis of language in use. As such, it cannot be restricted to the description of linguistic forms independent of the purposes or functions which these forms are designed to serve in human affairs. In the light of the functions which the forms are designed to serve, cautionary notices and their effects on road users in Nigeria are gathered and objectively scrutinized to set standard for this work.

\section{Review of Related Literature}

In discourse, every utterance is intended to serve a purpose. This was the motivation for (Fairclough 1992) claim that discourse is more than just language use and that it is language in use, whether speech or writing, seen as a type of social practice. The scholar observes further that discourse constitutes the social. According to (Candin 1997) discourse... refers to language in use, as a process, which is socially situated. However, we may go on to discuss the constructive and dynamic role of either spoken or written discourse in structuring areas of knowledge and the social and institutional practices, which are associated with them. In this sense, discourse is a means of talking and writing about and acting upon worlds, a means which both constructs and is constructed by a set of social practices within these worlds and in-so-doing both reproduces and constructs afresh particular social-discursive practices, constrained or encouraged by more macro movements in the over-arching social formation.

To add more to these definitions, one can say here that discourse refers to the use of oral and written language to specific audience, for specific purpose and in specific settings. Discourse refers to actual instances of communication in the medium of language. It is interested in analyzing the way sentences work in sequence to produce coherent stretches of language. Three major characteristics of discourse are: (i) appropriateness, (ii) purposefulness, and (iii) coherence.

(Olateju 2004) observes that the spoken and the written forms of language are different in their manner of production and point of production. Some believe that spoken form of language has advantage over the other. This claim underscores the belief that the writer has no access to immediate feedback. All he could do is to try to imagine the reader's reaction. Both spoken and written forms of language are central to discourse. What is dealt with in this work is what ( Halliday and Hasan ) refer to as texts and text linguistics, which according to them is the verbal record and analysis of a communicative act (roughly an act of communication or interaction). According to them, a text is 'language that is functional'. That is, language that is doing some job in some context as opposed to isolated words or sentences.

Commenting on text and discourse, Fairclough employs the term discourse to refer to the complete process of social interaction. Text is merely a sector of this process, because he considers three elements for discourse, namely text, interaction, and social context. In addition to text itself, the process of social interaction involves the process of text production and text interpretation. Hence, text analysis is a part of discourse analysis.

This said, inference could be drawn that cautionary notices on Nigeria high ways are not just mere text placed there. They are placed on the roads for specific purposes and targeted audience. Without doubt, given the attention and many efforts usually gone into this, it would only require little empirical facts to justify the functionalities of the text or linguistic land scale on our major roads.

Discourse analysis is a phenomenal concept for understanding society and human responses. It is also central to understanding language itself. Discourse analysis examines how language, meaning and society interrelate. Critical Discourse Analysis (henceforth CDA) "is the uncovering of implicit ideologies in texts. It unveils the underlying ideological prejudices and therefore the exercise of power in texts" (Widdoson, 2000; 2007).

Discourse analysis is a new area of importance and it has gradually moved from mere description of sentences to a 'scientific' aspect of academic study among other linguistic branches. According to (Brown and Yule 1998) "the analysis of discourse is, necessarily the analysis of language in use." Going by that, discourse analysis cannot be restricted to the description of linguistic forms independent of the purposes or functions which these forms are designed to serve in human affairs.

\section{THEORETICAL FRAMEWORK}

The study further expresses the theory that complements the topic of the research. The theory adopted in this work is to speech act theory, the choice of this theory is not unconnected to ( Hodge and Kress 1991) explanation that discourse analysis also includes the analysis of non-linguistic semiotic systems (systems for signaling meaning), non-verbal and non-vocal communication which accompany or replace speech or writing, performance art, sign language, and bodily lexis. 


\section{A. Synopsis of Speech Act Theory}

Scholars are in agreement that when people attempt to express themselves, they do not only produce utterances containing grammatical structures and words, they perform actions through those utterances. Actions performed through utterances are generally called speech acts. This concept was first set out by Austin in a book titled "How to do things with words". Such actions are commonly given more specific labels, such as apology, complaint, invitation, promise or request.

Speech act analysis is devoted to the study of utterances on the behavior of speaker and hearer, using a three-fold distinction. First, a communicative act which is the 'locutionary act'. Secondly, the act that is performed as a result of the speaker making an utterance, this is referred to as the 'illocutionary acts and they constitute the core of any theory of speech acts. Thirdly, the particular effect the speaker's utterance has on the listener, who may feel surprised, persuaded warned, etc. as a consequence. The bringing about of such effects is known as a perlocutionary act. When somebody speaks, he expected his hearer to recognize his/her communicative intention. Both the speaker and hearer are usually helped in this process by the circumstances surrounding the utterance. These circumstances including other utterances are called the speech event (Jaworski and Coupland 1999).

\section{B. Classifications of Speech Acts}

Speech act theory lends itself to establishing systems of classification for illocutions. Austin ( 1992) was cited in(Collinge, 1970) and (Fowler,1981) estimated illocutions classification number as between 1,000 and9,999. However, (Searle 1976 and 1979), improved on this classification twice as stated below:

\section{Searle 1976/1979 Classifications}

Searle's classification first came out in 1976. However, he reviewed it in 1979. The two classifications were not very different from each other, except a slight change of labels.

a. Representatives: The speaker is committed in varying degrees to the truth of a proposition e.g. affirm, believe, conclude, deny, report. In 1979, Searle renamed this group ASSERTIVES. Under this group, we can put statements of facts, assertions, conclusions and descriptions. E.g. 'The earth is flat' or 'The earth is spherical'. It is simply what the speaker believes to be the case or not.

b. Directives: The speaker tries to get the hearer to do something e.g. ask, challenge, command, insist, request, beg, etc. Searle retained the name in his (1979) classification. Here, the speaker uses this speech to get someone else to do something.

c. Commissives: The speaker is committed in varying degrees, to a certain course of action. In other words, he uses the utterance to commit himself to some future actions e.g. guarantee, pledge, promise, swear, threats, refusals, etc. They express what the speaker intends to do.

d. Expressives: The speaker expresses an attitude about a state of affairs. That is, he states what he feels about something. He expresses psychological states, such as pleasure, pain, likes, dislikes, joy, or sorrow. Such verbs as apologize, deplore, congratulate, thank, welcome, condole, etc are used in such cases. Searle retained the name in 1979.

e. Declarations: The speaker alters the external status or condition of an object or situation solely by making the utterance, e.g. I resign, I baptize, you are fired, war is hereby declared, you're excommunicated, I pronounce you husband and wife, etc. Searle retained the name in 1979.

\section{Components of Speech Acts}

Usually, the action performed by producing an utterance consists of three related acts. These are examined below.

1. A Locutionary Act: The basic act of utterance or producing a meaningful linguistic expression (i.e. sound structure, grammatical structure and semantic structure) is referred to as a locutionary act. An individual who finds it difficult to form the sounds and words to create a meaningful utterance in a language (for example, because the language is foreign might fail to produce a locutionary act).

2. Illocutionary Act: When we produce well-formed utterances, we do so with a purpose in mind, the function in the mind of the speaker which his utterance is expected to perform is referred to as the illocutionary act. It focuses on the content of the message which is designed to provide a certain effect based on the intended function as conceived in the mind of the speaker or writer. The interpretation which the listener puts to it, that is what the statement counts as is the Illocutionary force of the utterance.

3. The Perlocutionary Act: This is the effect we expect our utterance to have on our listener. Simply put, it is the effect of the utterance on the hearer e.g. happiness, surprise or amusement. It is also generally referred to as the perlocutionary effect. However, it is worthy of note that the illocutionary force of an utterance and its perlocutionary effect may not coincide. For instance, if somebody is invited to take a meal with the utterance above, he may or may not take the meal.

\section{Felicity Conditions}

(Crystal 1987) opines that speech acts are successful only if they satisfy several criteria, known as felicity conditions. These conditions are classified into five as follows: the preparatory condition, the sincerity condition, the content condition, the general condition, and the essential condition. It is our aim in this lecture to examine these conditions in 
details. Felicity conditions are conditions that must be satisfied if a speech act is going to be successful. These conditions are classified into five, each of which is discussed briefly below:

1. General Condition: This presumes that the speaker or writer (as the case may be) is not play-acting or not being nonsensical. In other words, the writer shows a reasonable level of seriousness which is devoid of play-acting or clowning. The tone of the speaker is such that cannot be taken for granted. This condition constitute an important condition on the use of such verbs as fine, baptize, arrest and declare war, which could only be used by a judge, a priest, a policeman and a war general or head of state respectively.

2. Content Condition: Content condition as a type of felicity condition entails the content in a speaker's utterance that can actually bring about the reality of his utterance, which can be present or future occurrence. Such verbs like warn, promise, etc are used. For promise, it is a future act of the speaker.

3. Preparatory Condition: As the name implies, this kind of condition talks about preparatory statements which can be a warning against a future occurrence. The peculiarity about preparatory condition is that an occurrence does not happen by itself, there must be an agent to carry it out. For a verb like 'promise' (i) the event will not happen by itself (the speaker will make it happen) (ii) it will have a beneficial effect on the hearer. For a verb like warn on the other hand (i) it is not clear that the hearer knows that the event will occur (ii) the speaker thinks the event will occur (iii) the event will not have a beneficial effect. Misfire occurs when this condition is flouted.

4. Sincerity Condition: This type of condition places emphasis on the sincerity of the speaker in the speech act. It also justifies the fact that the speaker is not play acting. It shows that the speaker is damn serious and committed. For instance, a verb like 'promise' connotes that the speaker genuinely intends to carry out the future action. 'Warn' on the other hand connotes that the speaker thinks the event will not have a beneficial effect. For instance, in William Shakespeare's play, 'Julius Caesar', the soothsayer warns Caesar to beware of the ides of March. That was the day Caesar was assassinated eventually because he did not heed the warning. Abuse occurs when this condition is flouted.

5. Essential Condition: This type of condition explains the need to certify certain imperatives for a future event to occur. It provides the necessary information about a future event. Breach of commitment occurs when this condition is flouted.

\section{METHODOLOGY}

Purposive survey method is used to generate data for this work. A great deal of the data was supplied by the researchers adapting some of the road signs from different geographical locations in the country while the remaining pictures were randomly selected on social media. In analyzing the data, the researcher focuses on proposed Fairclough's three aspects of discourse. According to (Fairclough 1989), highlighted below are the three dimensions for CDA:

i . Description is the stage which is concerned with formal properties of the text.

ii. Interpretation is concerned with the relationship between text and interaction by seeing the text as the product of the process of production and as a resource in the process of interpretation.

iii. Explanation is concerned with the relationship between interaction and social context, with the social determination of the process of production and interpretation, and their social effects.

Each of the available data is presented in picture format and the analysis is done underneath. The analysis combines the three aspects of discourse together in one structural frame. It includes labeling the formal properties of the text and treats same as an object. In the same vein, it indicates the relationship between the text, the social events and the perlocutionary force of the text. The data is systematically presented with regards to (Searle 1976and 1979)'s Classifications of speech Act.

\section{Data PResentation AND ANALysis}

Discourse analysts consider the larger discourse context in order to understand how it affects the meaning of sentence. C. Fillmore posits that two sentences taken together as a single discourse can have meanings different from each one taken separately. We therefore present a critical analysis of selected cautionary notices using appropriate discourse features as we examine the linguistic contexts of these notices as captured on selected highways in Nigeria in order to establish the illocutionary and perlocutionary effects of these notices as well as the ethno-linguistic patterns and variables of these cautionary-linguistic notices. 


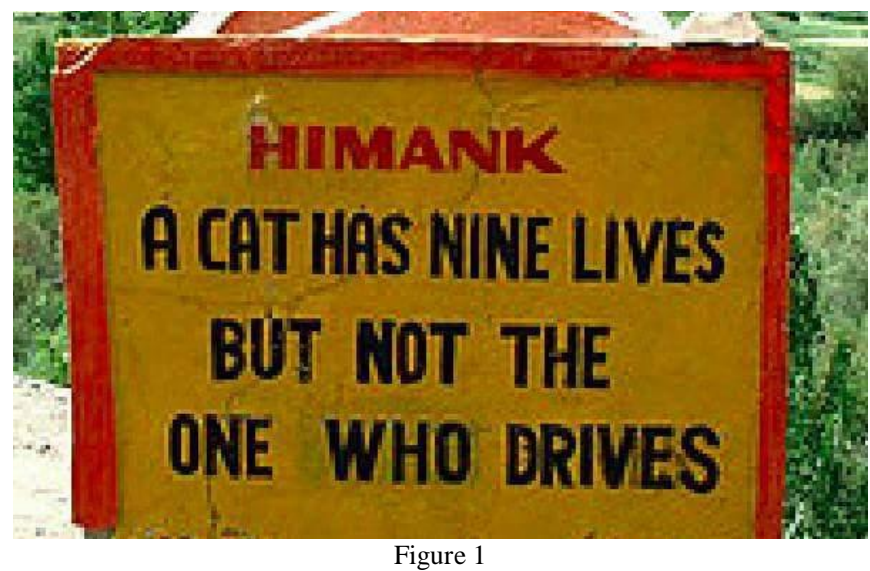

Figure 1

The warning on the sign post reads:

“A CAT HAS NINE LIVES BUT NOT THE ONE WHO DRIVES”.

The warning is written in block letters against a sign post in yellow background with red border. This cautionary notice makes use of an idiomatic expression that is familiar: (A cat has nine lives). It however adds another twist to the idiomatic expression (but not the one that drives). The caution draws the attention of the driver not to be reckless in their driving, as they cannot be likened to cats that live a reckless live and as such throw caution to the winds. The cautionary notice their makes the driver to be more conscious of his driving. This statement also goes beyond its ordinary meaning as it would provoke the thought of the driver to the fact that humans only have one life to live and it needs to be guarded jealously. The notice would help the driver observe all safety measures so as to help him preserve his life. Its are to help road users take caution on the/road.

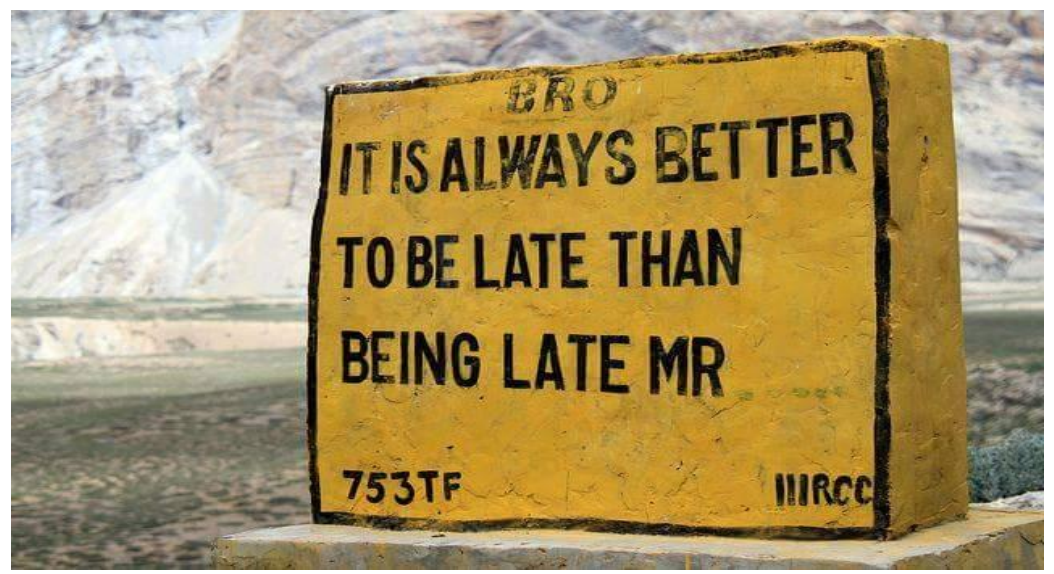

Figure 2

In this cautionary notice, the words are written in block letters and they are; "IT IS ALWAYS BETTER TO BE LATE THAN BEING LATE MR". The words are written in black on a built square signpost with a yellow background and black border. In the picture above, the words on this cautionary notice is cautioning the driver that it is better for him to get to where he is going late, than for him to move at a high speed (in order to get there on time) and end up dead. The message gives a strong warning to the driver about how precious his life is.

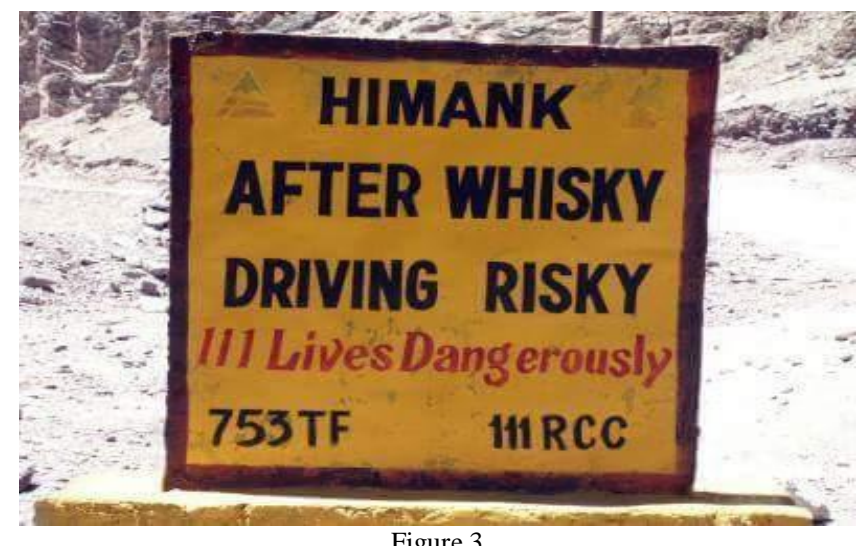

Figure 3 
The picture above reads "AFTER WHISKY, DRIVING RISKY'. This signpost is written in black ink and on a yellow painted surface to serve as a caution notice to drivers. The statement helps to emphasize the dangers of taking excessive alcohol before driving. It only helps to put it in a better way, not that it is only after taking whisky but after taking alcohol generally. It would attract a driver's attention to read and heed to it than a regular caution that says" don't take alcohol before driving". This notice is positioned to caution drivers against taking alcohol before or while driving, as alcohol makes driving risky and dangerous. The notice performs a representative act as it present a simple fact to the road user.

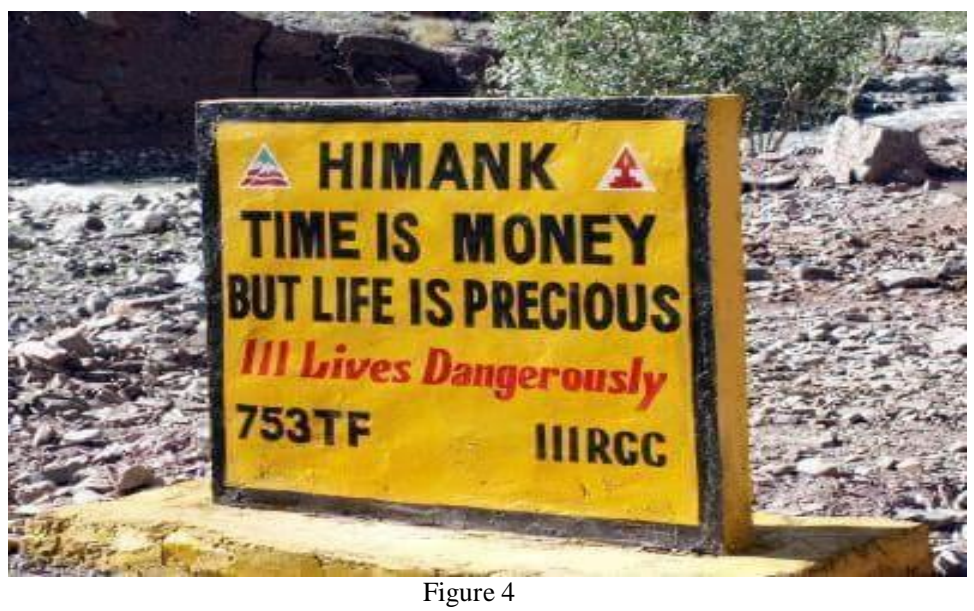

The first message on the cautionary notice is written in block letters which is "TIME IS MONEY BUT LIFE IS PRECIOUS". The words are written in black on a built square sign post with warning signs. The signpost has a background of yellow. The words written in small fonts in the post "Lives Dangerously" are written in red. The cautionary notice is sensitizing the driver that although he wants to get to where is going on time probably because of business but his life is much more important than whatever he is going to do. The message is trying to tell the driver a time lost can be regained but a life lost can never be regained.

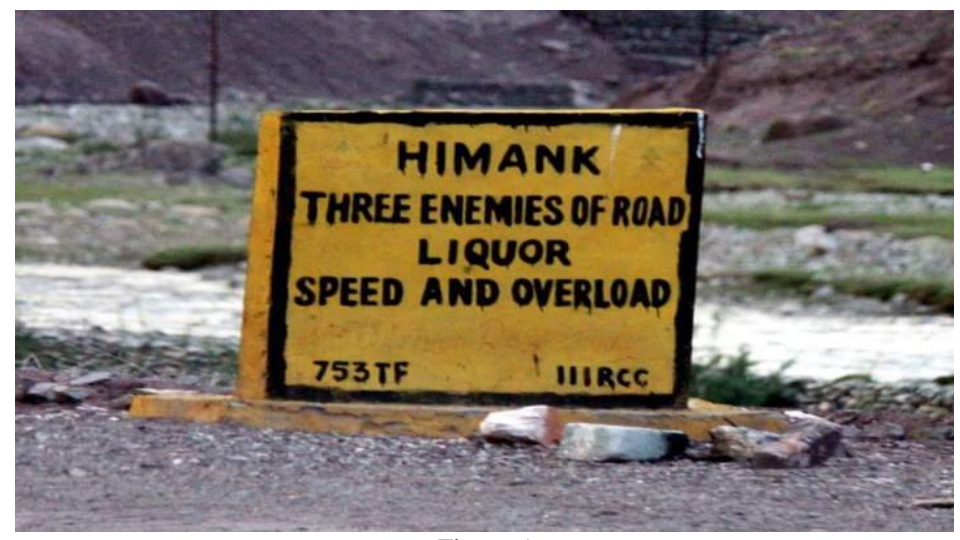

Figure 5

In the picture above is a caution notice that reads "THREE ENEMIES OF ROAD LIQUOR SPEED AND OVERLOAD" written on a signpost with a black boarder and it is placed by the road side. The message on this notice is highlighting the three major things that all road safety caution emphasize on which will lead to an accident if not avoided. Intake of excessive alcohol (liquor) before driving, over speeding on the road, overloading of goods, passengers portends grave danger on our roads. All of these are the major caution that drivers need to adhere to. The message is direct and simple.

The cautionary notices in this category are propositional. They affirm and state a belief that it is better to arrive at where the road users are going behind schedule than to drive recklessly and end up being late. The second notice concludes that driving is risky after whisky. They are simply assertive. The third text states that life is too precious to be taken with levity because of any other valuables. The fourth asserts that liquor, speed and overload make road unsafe. All these, without doubt, are what the writer belief to be the case. By implication, this means that over speeding, overload and liquor are hazardous to driving. The common effect of this is the declined in speed by the road users as soon as they spot the notice. This effect is technically called perlocutionarty force in discourse.

These are referred to as directive act because they all seek to get the road users to do something. The texts ask, challenge, command, insist, request, and beg the road users to perform one action or the other. Texts in this category 
call for a restrained driving, implore road users to do nothing while driving and go slow to avoid accident. As posited by Searle, the texts are placed on the road side to persuade people to embrace the suggested course of actions. Again, the common effect of this is the declined in speed by the road users as soon as they spot the notices. This effect is technically called perlocutionarty force in discourse.

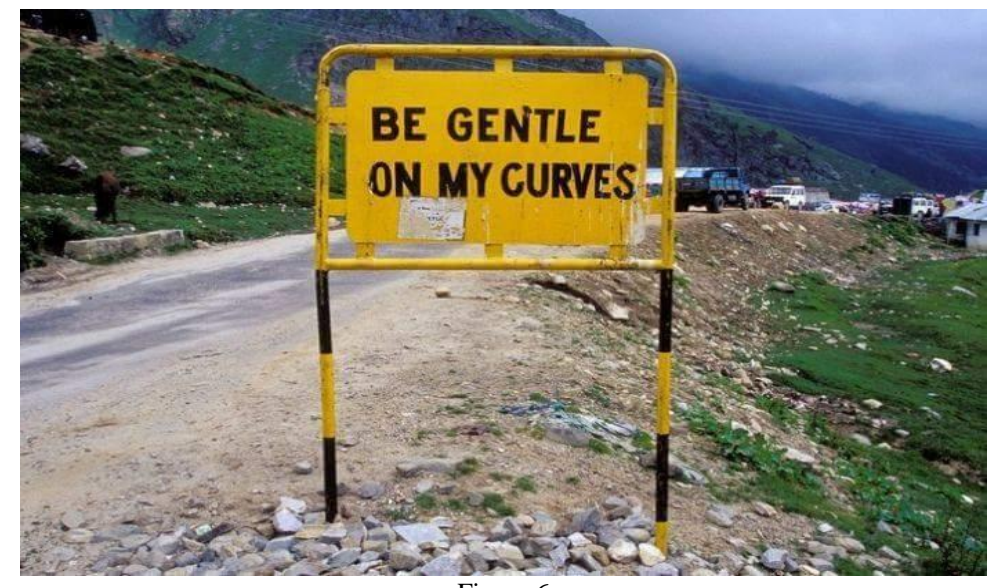

Figure 6

The picture above, these words are written in block letters "BE GENTLE ON MY CURVES" The words are also written in colour black on a square signpost and a yellow background. In this picture we can also see a road with bad curves. In this cautionary notice, the message is sensitizing the driver to tread carefully on that particular road because the curves are dangerous and a car can fall off the cliff if the road user is not careful on it. The message is cautioning the driver to beware of the curves on that particular road.

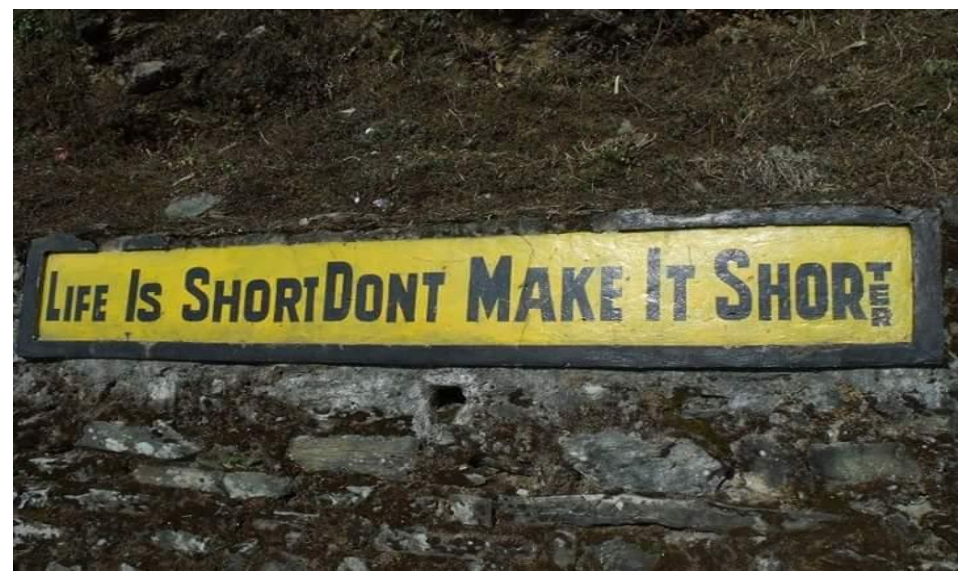

Figure 7

“LIFE IS SHORT DON'T MAKE IT SHORTER”. This means that although life is short, don't cut it shorter. Don't die before your time.

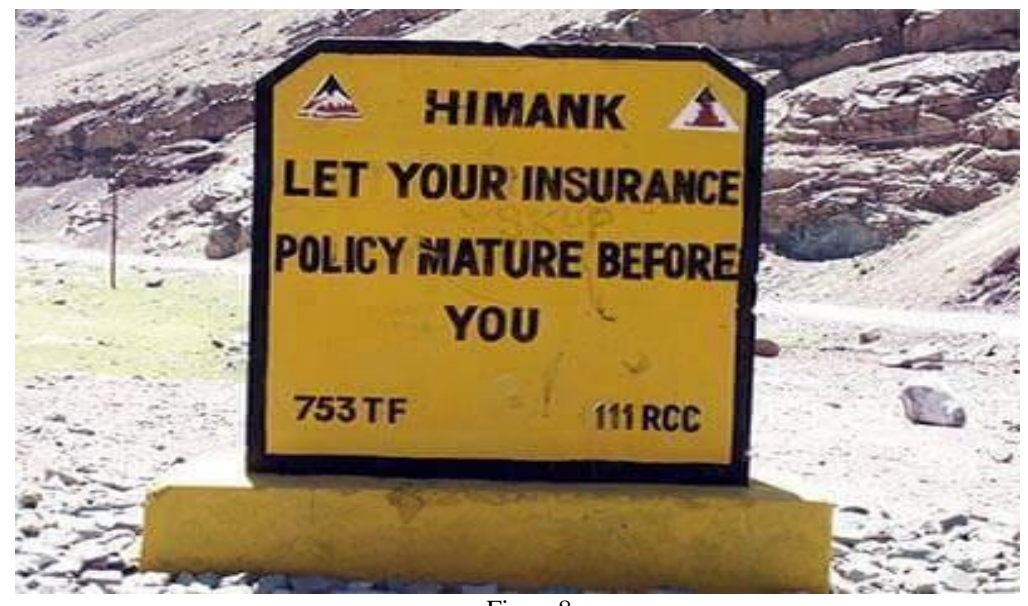

Figure8 
"LET YOUR INSURANCE POLICY MATURE BEFORE YOU”: warning to the driver to take it easy so that he/she will not die young. It performs directive roles as it requests the driver allow the insurance policy for either the car or his life get matured before he dies. The language is simple and direct. Its perlocutionary effect on the drivers is to drive with caution and take safety seriously. Even if you have a death insurance policy, you should not be reckless with your life while driving. It warns the driver to drive carefully on the road.

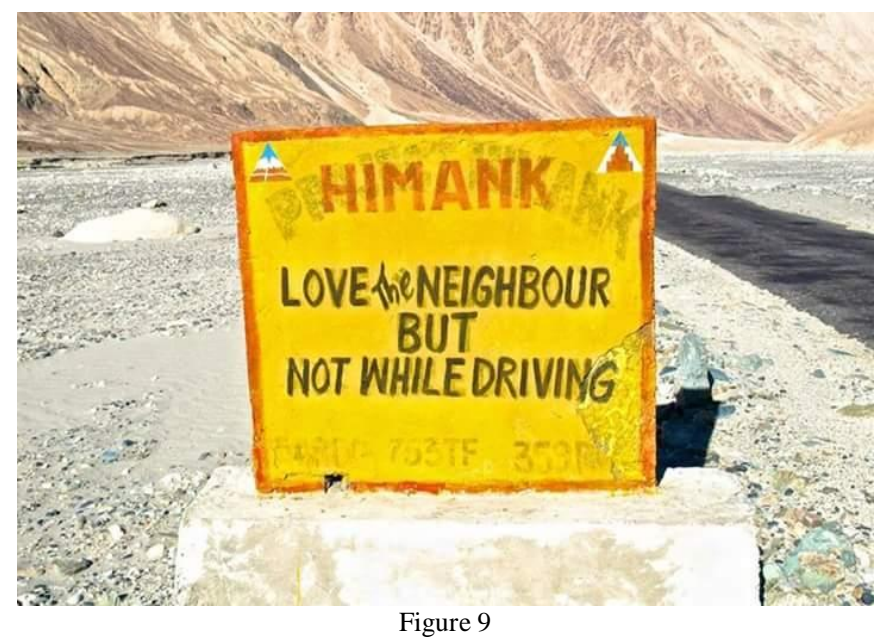

This notice is placed on a square yellow board placed on the road side. It inscribes "LOVE THE NEIGHBOR BUT NOT WHILE DRIVING". This is actually addressing couples who are driving. It means the driver should concentrate and not be distracted by his or partner sitting beside him/her. The caution is that in order to prevent accident from occurring, the driver needs to focus on the driving and not on the person sitting beside him/her, who may likely be his/her partner.

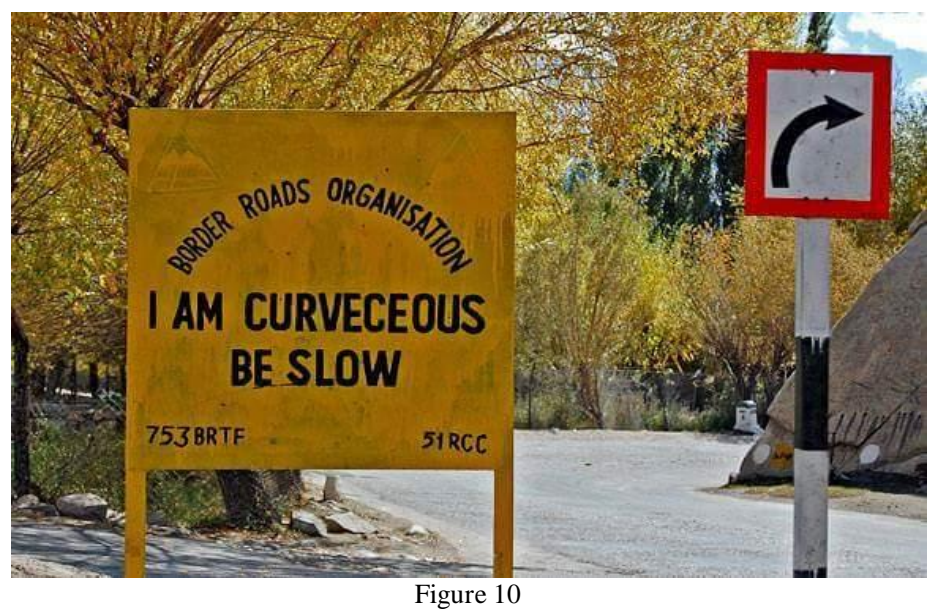

The picture above on the cautionary notice states: "I AM CURVACIOUS, BE SLOW".

The message on the cautionary notice is simply directing a driver to what is ahead. In this case, a driver may be driving safe already but then ahead of the road are corners and curves where the driver needs to be slow to successfully pass the drive way without hitches. This message will clearly help such driver to be safe. The message is positioned for curbing over speeding and promoting safe driving. Its force is light and neutral. Its possible effect is to caution over speeding. It performs a directive act. 


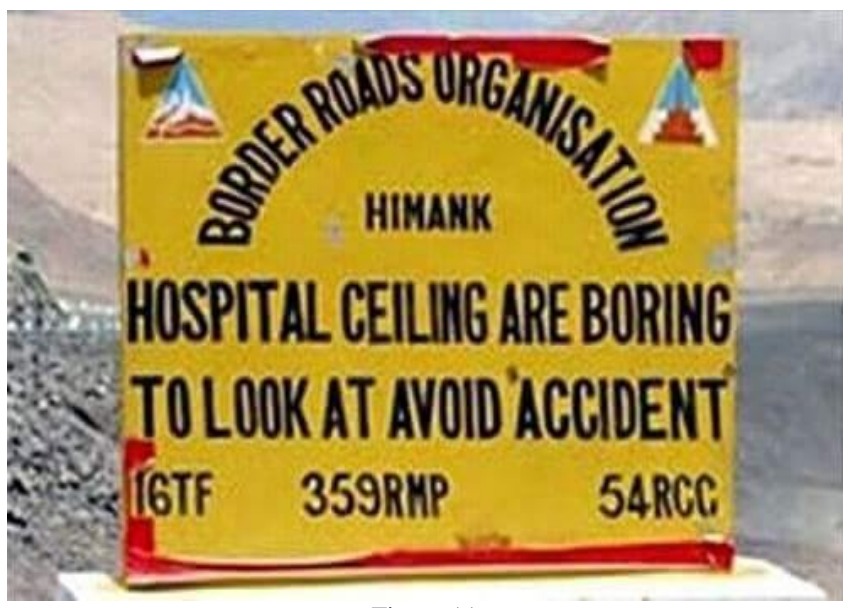

Figure 11

The warning notice on the sign post reads: "HOSPITAL CEILING ARE BORING TO LOOK AT AVOID ACCIDENT". The warning is drawn on in block letters on a sign post with a yellow background without borders. The color selection for the font is in black. The notice is drawn up by the border roads organization. The cautionary notice on this sign post cautions drivers behind the steering wheel, of the imminent boredom awaiting anyone that is unfortunate enough to be involved in a motor accident. The notice beckons on the driver to avoid accident, so as not to spend time in a hospital room staring at the ceilings. This is a weighty one as it persuades the driver to avoid accident as much as possible to avoid being tied down on the hospital bed no matter how mild or fatal the accident may be. The statement is directive as it could help the driver avoid fatal accident by either avoiding alcohol or over speeding.

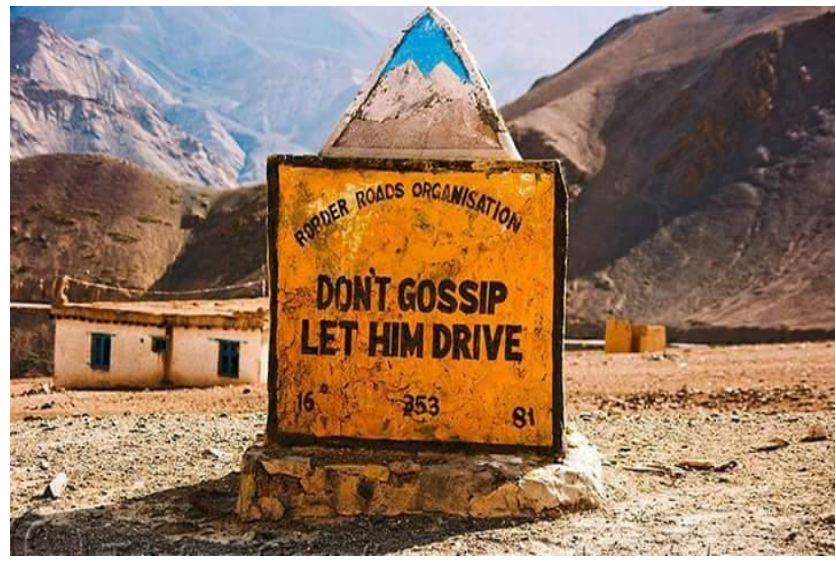

Figure 12

The above is a warning that reads: "DON'T GOSSIP, LET HIM DRIVE". The warning is written in block letters on a square signpost post with yellow background and black border. The message in this cautionary notice is not completely directed at the driver, but whoever is seated with the driver in the vehicle. It is a message designed for the passengers in the vehicle. It begs on the passengers not to distract the driver from driving, it cautions them from engaging the driver in gossips or side talk. Also as gossiping is widely associated with females, this message cautions wives, aunties, mothers, girlfriends and the entire female population not to engage their driver whether male or female in discussions or gossip while the individual is driving. It cautions them to allow the driver do his job, which happens to be driving at that particular point in time. The force of this notice is light and persuasive while its effect is poised at optimal concentration on the part of the driver. 


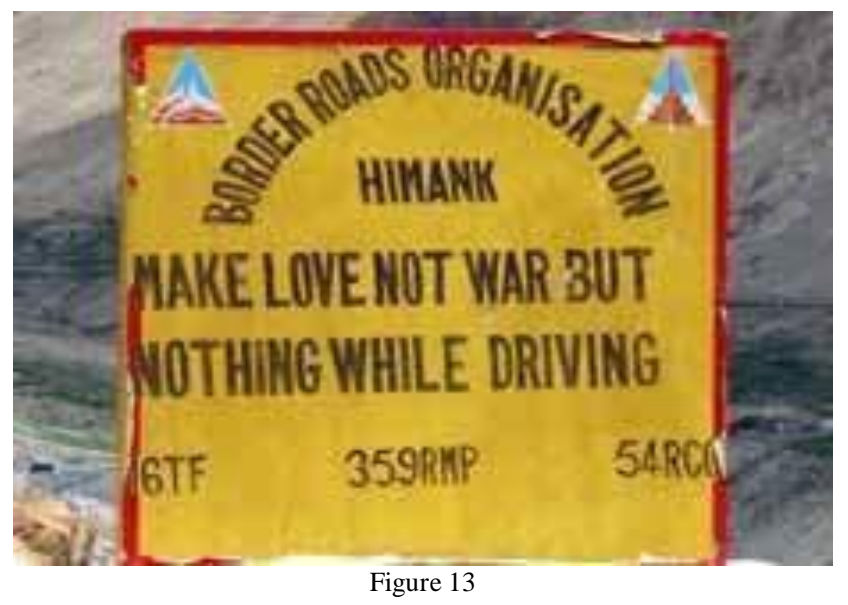

This picture states: "MAKE LOVE NOT WAR BUT NOT WHILE DRIVING". This image is a road safety caution boarder roads organization written in black boarder on a yellow surface with red paints at the edge signifying danger if message not adhered to. The statement on the notice is drawing the driver's attention to always make peace with whoever is a passenger on board. On the other hand, it could also be talking to a couple who are travelling should forget their emotions and quarrels while driving till they get to their destination safely.

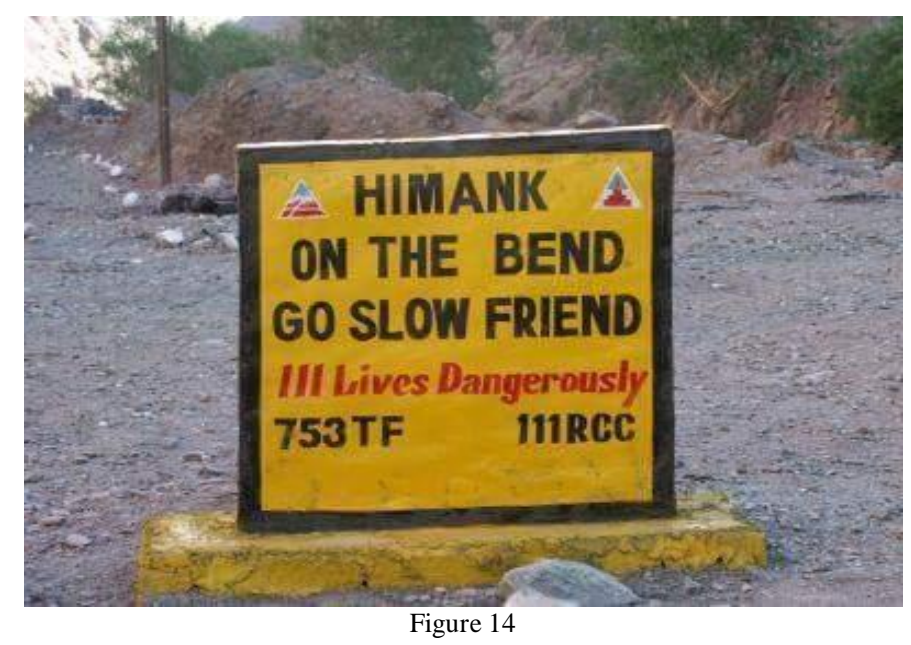

This inscription is written in a square box with yellow backgrounds and black borders. The words on the sign post reads thus: "on the bend, go slow friend... lives dangerously". Red color was used for the words to indicate the importance as well as the danger warnings that the words carry with them. Warning signs or cautions generally indicate any potential hazard, obstacle or condition requiring special attention. The notice however alerts the driver or road user of a bend ahead of him in order to take caution. The caution draws the attention of the driver to a bend that lies ahead of the road, and it therefore calls the attention of the driver to drive slowly while driving through the route. This notice perform a directive role as it politely persuades the driver to drive slowly. The use of "friend" however makes it seem like a conversation. Its perlocutionary force is light and persuasive.

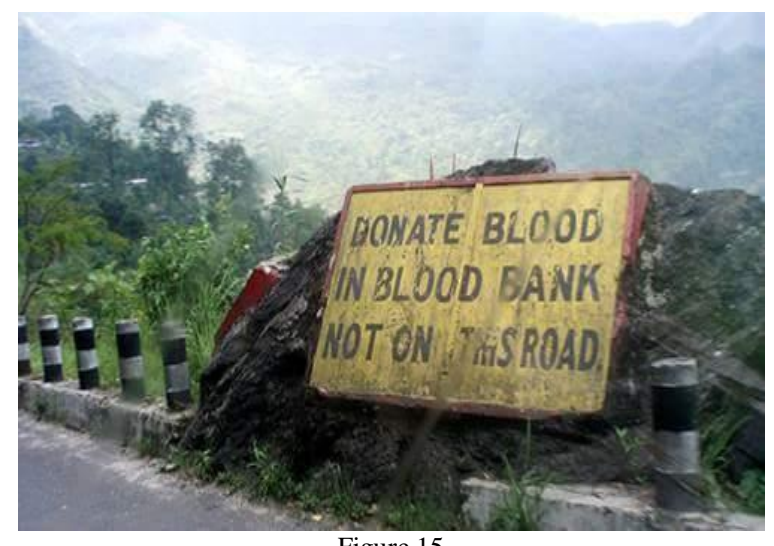

Figure 15 
The inscription says: "DONATE BLOOD TO THE BLOOD BANK AND NOT ON THIS ROAD”. The warning is that one should try as much as possible to prevent accident on the road. When accident occurs there would be lost of blood and probably lives too. When a driver or other road users sight such caution, he/she will think of nothing but accident. Although, the caution does not mandate people to donate blood at blood banks but to know how it is of no use to drive recklessly and lose blood at the end in an ironic manner. The message is positioned to help drivers avoid blood spill on the road. The meaning of the statement however goes beyond its literary meaning. It also persuades the driver to try as much as possible to avoid blood spill but rather donate the blood to blood bank in hospitals to save other people's lives.

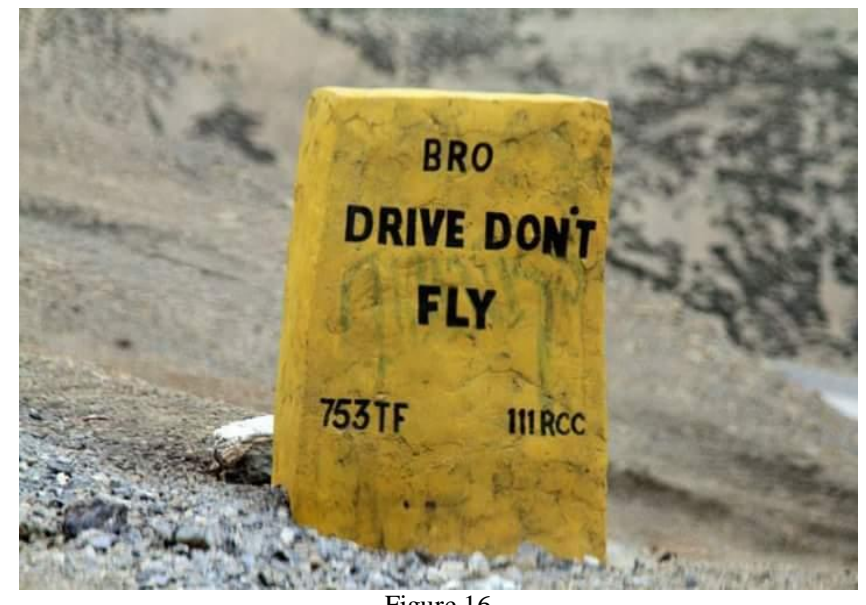

Figure 16

In this picture, the words "BRO DRIVE DON'T FLY" are written in block letters with the colour black on a built square signpost with a yellow background. In the cautionary notice above, the message is simply telling the driver that road is meant for driving, not for flying, which by implication connote over speeding. Motorists are enjoined to realize that their responsibility is not just driving, but driving at a normal speed. The message is telling the driver that he should not over speed.

The above linguistic landscape are grouped together and referred to as directive act because they all seek to get the road users to do something. The texts ask, challenge, command, insist, request, and beg the road users to perform one action or the other. Texts in this category call for a restrained driving, implore road users to do nothing while driving and go slow to avoid accident. As posited by Searle, the texts are placed on the road side to persuade people to embrace the suggested course of actions. Again, the common effect of this is the declined in speed by the road users as soon as they spot the notices. This effect is technically called perlocutionarty force in discourse.

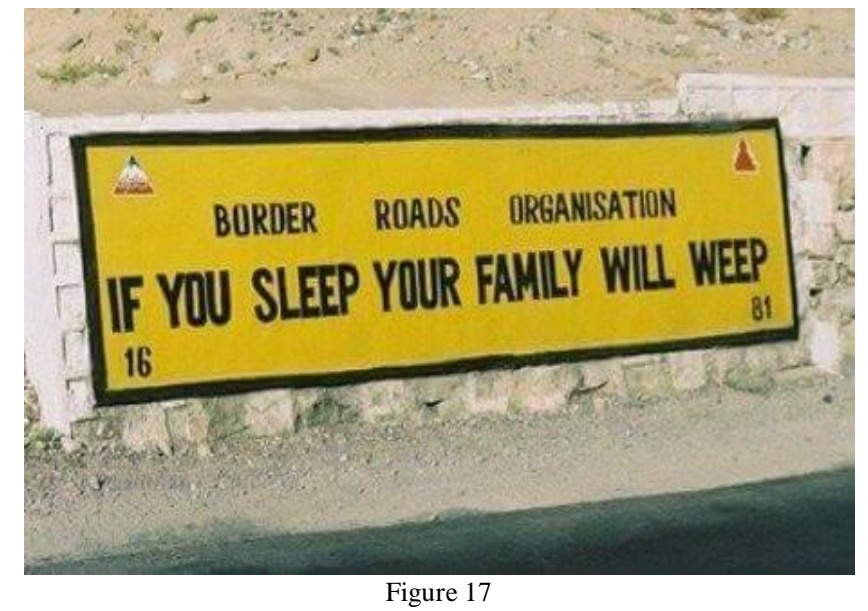

In the picture above, the cautionary notice reads "IF YOU SLEEP YOUR FAMILY WILL WEEP". The cautionary notice is written in block letters on a rectangular signpost with a yellow background and black border, with the font color of the notice in black. This message in this cautionary notice can be safely said to be designed for a family man. The message cautions the driver to avoid sleeping while driving. It's best to park the car by the roadside and take a short nap if it is necessary. The cautionary notice also sensitizes the driver to the possible fate that awaits his family if he fails to take necessary precautions while driving. It could also mean that if the driver dies (sleep on) his family would eventually weep over him. The meaning of the statement goes beyond its conceptual meaning. The message in the cautionary notice is a powerful one that begs on the sense of responsibility of the driver to his family. 


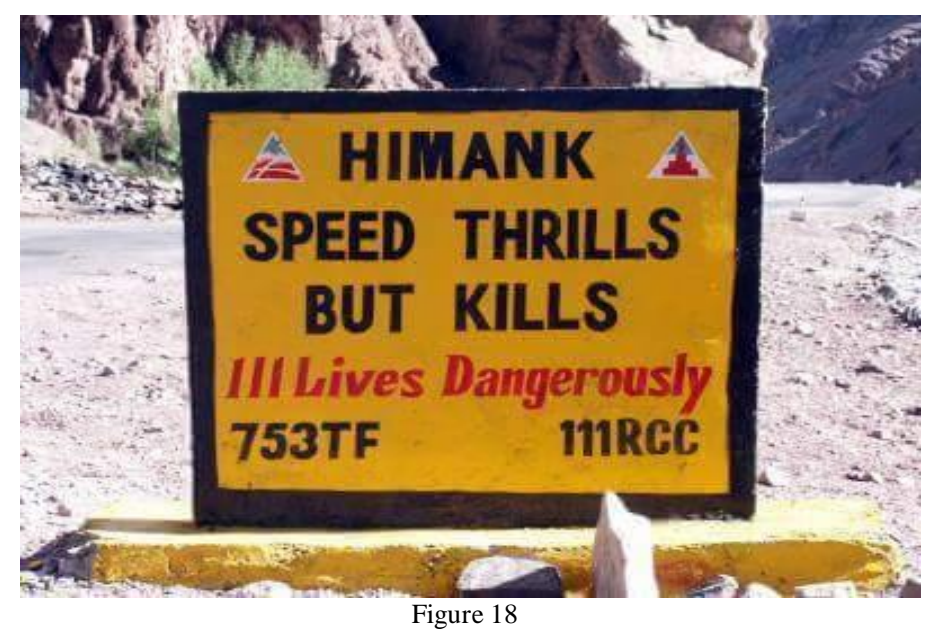

"SPEED THRILLS BUT KILLS": This means that although the driver may enjoy speed but the result may be death from accident. This, in a way, suggests that when the driver speeds, he will be enjoying himself but there is a danger inherent in it as this may lead to accident and consequently untimely death.

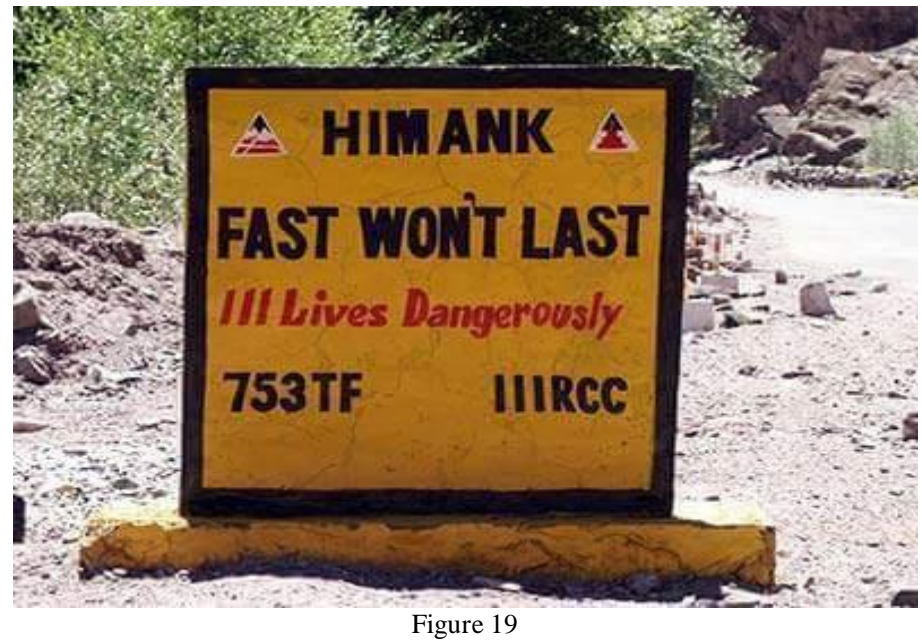

The warning is written in black print on a yellow squared board. The caution reads "FAST WON'T LAST". This simply means that speeding can kill and it is better to take it slowly. The caution does not come in its locutionary form rather it is written in such a way that the reader could decode the meaning and might take a perlocutionary act by reducing his/her speed. The language is simple and direct. Its effect is to help driver reduce speed. It persuades the driver avoid over speeding as it won't help the driver last long.

The above items are the cautionary notices that state the writers' commitment to several degrees of actions. The texts perform serious speech functions ranging from pledge, swear, and threats. By description, altogether, the notices are commissive Acts. Such words as "weep", "kills", and "last" which appeal like threats and swear confirm this claim. By virtue of interpretation, one of the text reveal that sleeping while driving is deadly and could lead to disastrous occurrence capable of making the loved ones of those who sleep while driving to shed tears. Another text shows that speed kills even though it is pleasurable while a number of the notices stress that those who speed would not last. This simply underscores the maxim: haste makes waste. Lastly, the speech act briefly explains that sleep and speed are instrumental to roads' mishap and seek to make people desist from them. The usual effect of this act is the declined in speed and improved consciousness of the road users. This effect is technically called perlocutionarty force in discourse.

The texts of the data presented in this work express the writers' attitude about a number of states of affairs. Hence, they are tagged Expressive Act. Besides, they state psychological states or mind set of the writers toward such issues as immodest, unsafe, hurried and rally-like kind of driving. The texts condemn these and cautioned road users against reckless driving. Above this level, the fourth text in this group apology. To submit, all in all, the texts seek to make people to conform with modest, safe, calm and ethical ways of driving. 


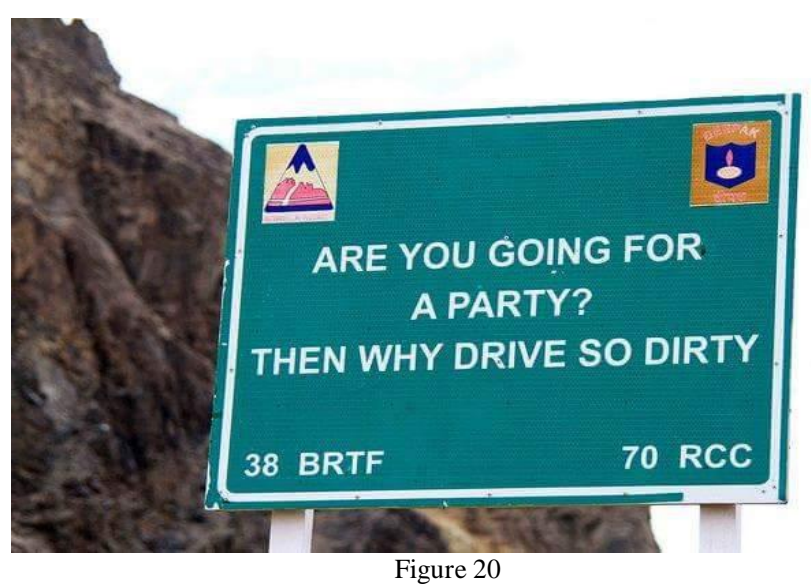

“ARE YOU GOING TO A PARTY? THEN WHY DRIVE SO DIRTY” The words are written in block letters in white colour on a square signpost, the background on the signpost is blue with a white border. Looking at the picture, the message on this cautionary notice can be said to be talking to a driver probably on his way to a party. This message therefore gives the driver a kind of sense that, after all, he is going to a party and he is definitely going to get so much fun when he gets there, so, why don't he just play safe on the road and take it easy while driving on his way to the party.

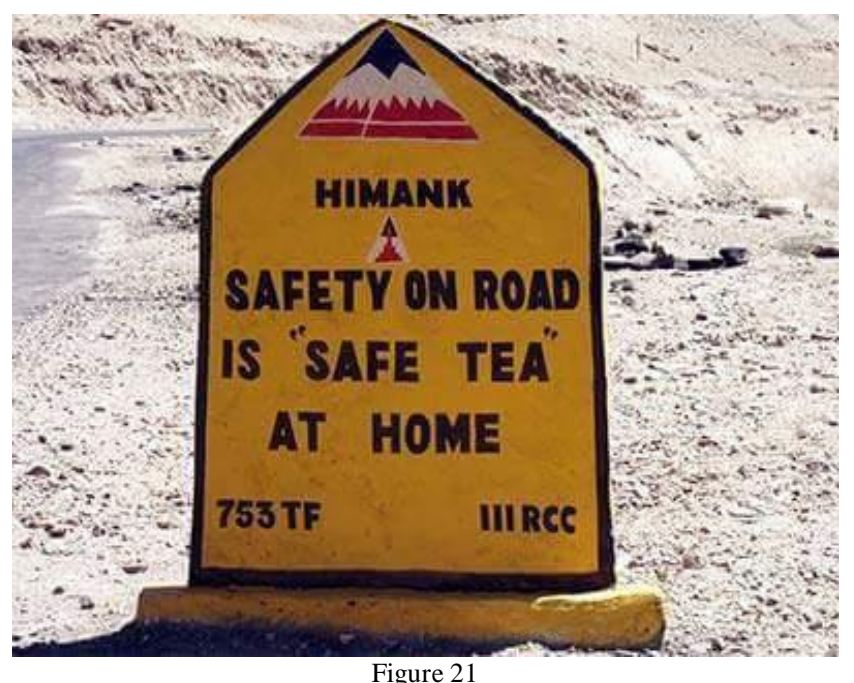

In this picture is a caution notice that reads "SAFETY ON THE ROAD IS "SAFE TEA" AT HOME". It is written with a black boarder on a yellow surface by the road side. The statement is asking drivers to always drive with caution so as to arrive home safely. Meeting "safe tea" at home may not literarily mean tea in the real context, but to get home safe. The message is sent to caution the driver and to promote safety as we know that safe drive on the road is a safe live in the home.

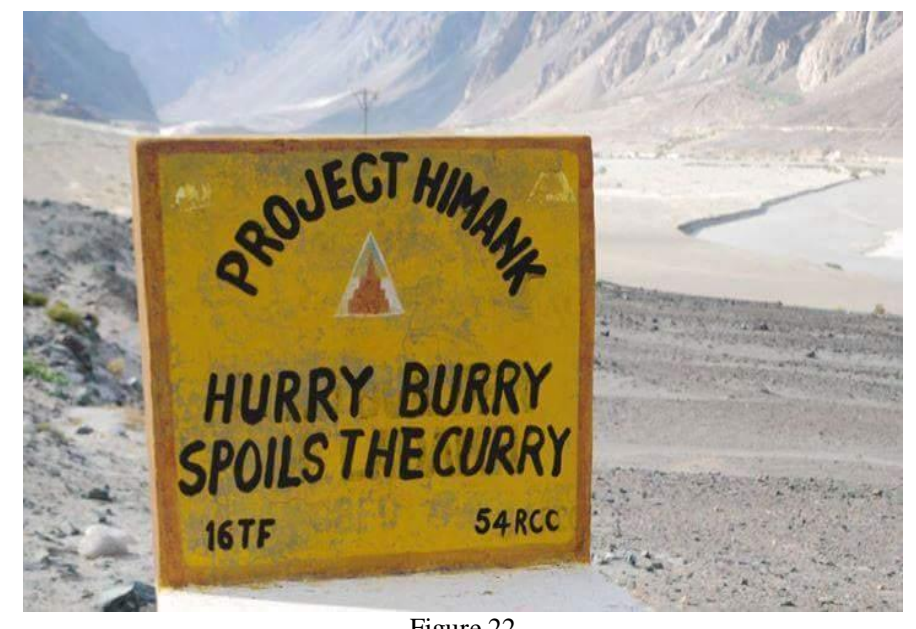

Figure 22 
In the picture above, the notice states "HURRY BURRY SPOILS THE CURRY". It is placed by a road side and it is written in black ink on a yellow painted surface taped with red colored edges. The message is directed to drivers that are always in a hurry to get to their destination. The caution notice is bringing such drivers to their senses when they pass such route where the sign post is placed. This will help the driver in reducing the level of speed. The statement employ literary device of alliteration. The message can be interpreted to be an impatient man would eventually spoil the fun of life. The message is however used to curb over speeding on the highway. It also notes that speed would only spoil the goodness of the driver. The words are simple but indirect and its perlocutionary effect would be moderation in speed level.

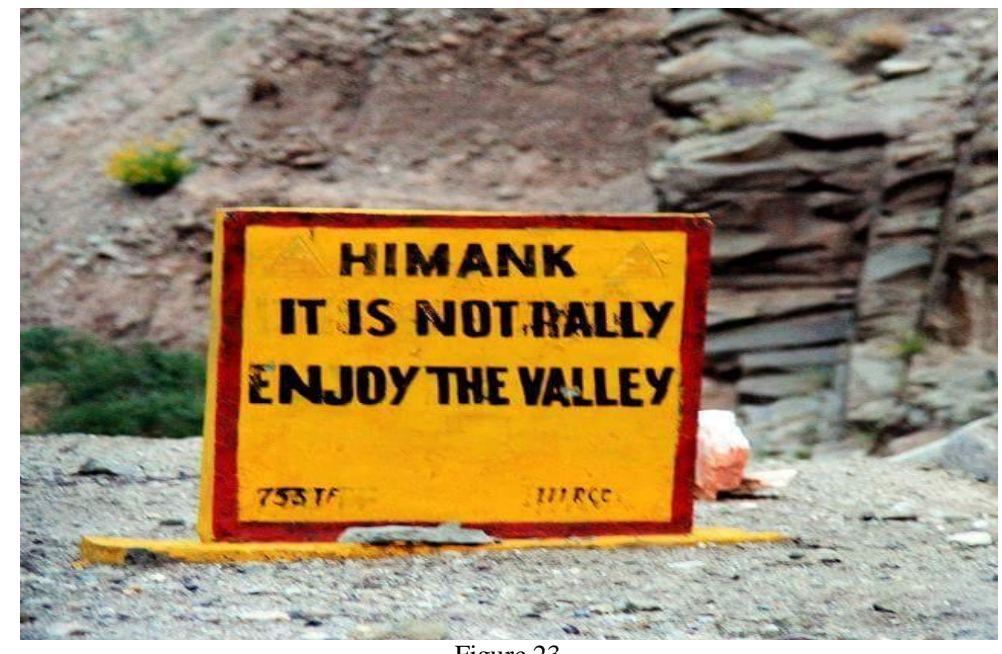

Figure 23

This warning notice on the sign post reads “IT IS NOT RALLY, ENJOY THE VALLEY". Like the preceding images, the warning on this sign post is also drawn up against a square shaped sign post with yellow background and red border, with the fonts in black colors. This notice is put up to call the attention of the driver to a fact that driving on a highway is different from driving during a car rally. A rally is a motor racing event in which drivers run at high speed in order to get to the finishing line before the others, and in which casualties are often recorded, because the winner is usually the driver who arrives at the finishing line within the shortest cumulative time. This notice beckons upon the driver to enjoy the drive as he/she travels on the valley i.e the driver ought to drive at a minimal speed. The notice is positioned to help the driver curb over speeding and just enjoy the ride. The perlocutionary force is light while its possible effect is to curb over speeding.

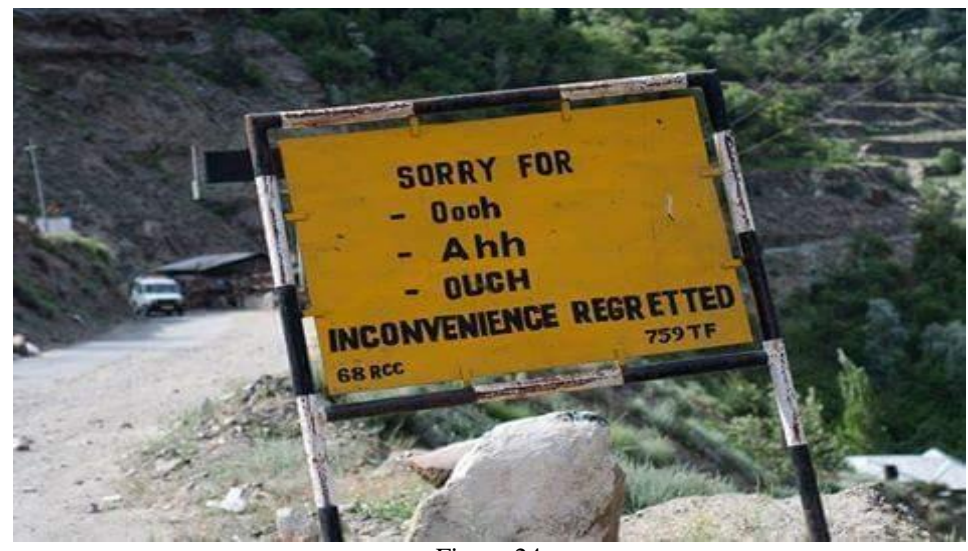

Figure 24

In this picture, the words on it are: "SORRY FOR, OOH, AHH, OUCH. INCOVENIENCE REGRETTED". Some of these words are written in small fonts while the last message on the notice is written in block letters. The words are written in black colour on a square signpost with a yellow background and black and white color on the pole. We can also see a bad road and a big car coming in the picture. The cautionary notice is sensitizing the driver to the reality of a very bad road. The words "OOH, AHH, OUCH" are used to sensitize the driver of the pain he will feel if he is not careful on that road. The message on this cautionary notice is not written in straight words to sensitize the driver on the condition of the road, there are even words of apology for whatever happens to the driver. 


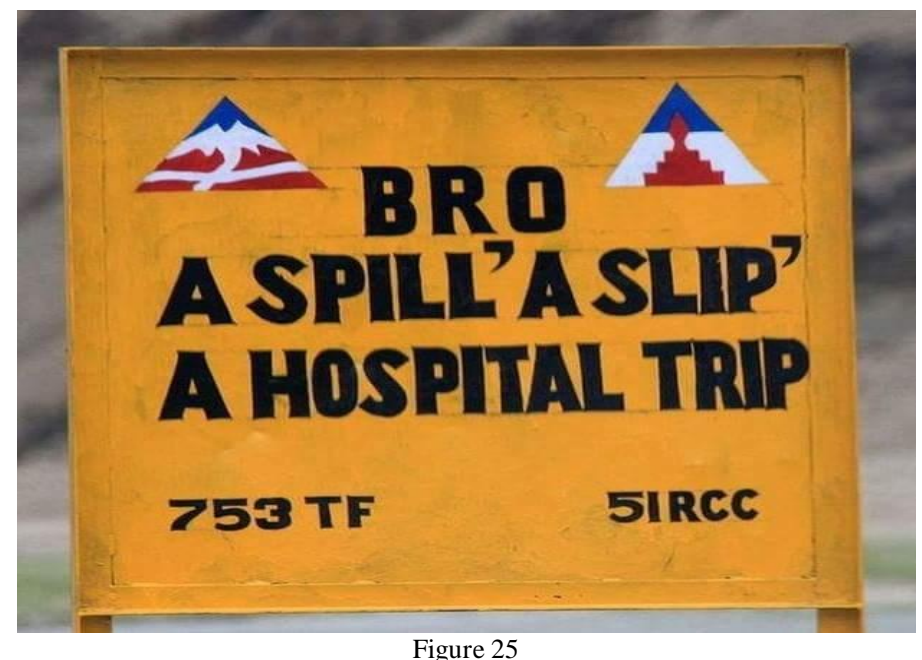

Figure 25

In the picture above, the cautionary notice reads: “BRO A SPILL' $\boldsymbol{A}$ SLIP' A HOSPITAL TRIP". It is written in blank ink on a metal, painted in yellow. The message is talking to a male driver as it indicates 'Bro" meaning he can't afford to make any silly mistake while driving as it will lead to an accident. So the notice is a caution to the driver as he sees it, he would drive with caution so as not to land in the hospital. The message is posted for safety and caution. It performs a directive act.

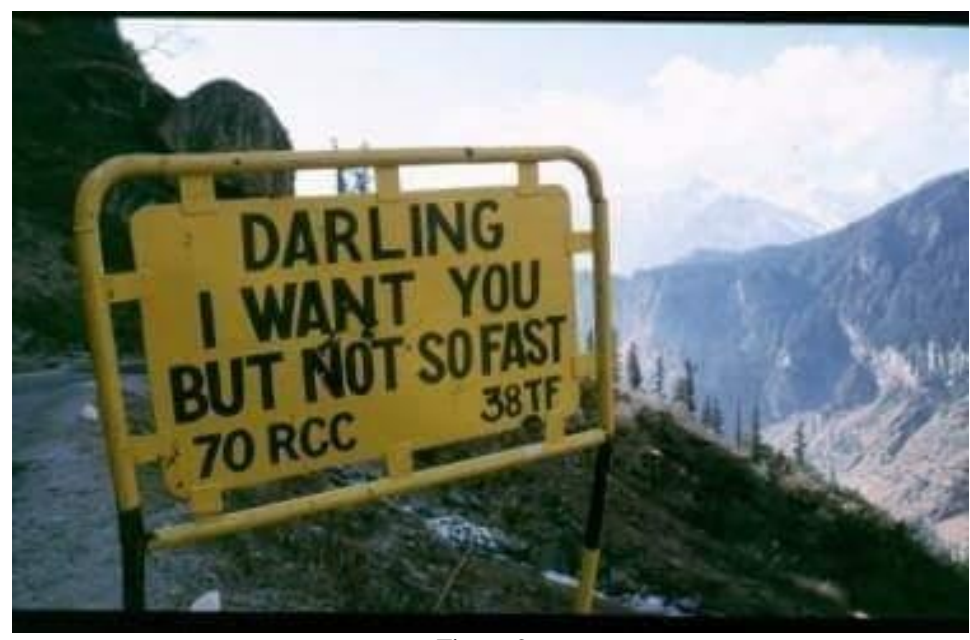

Figure 26

"DARLING I WANT YOU BUT NOT SO FAST": The words are written in block letters and in black colour on a rectangular signpost with a yellow background. The message written on this cautionary notice can be said to be designed for a man going to see his wife, his girlfriend or a lover. The words on the signpost are used to caution the man not to drive too fast to his destination because he is still going to get there even if he is moving at a slow pace. The cautionary notice is trying to tell the driver not too rush himself.

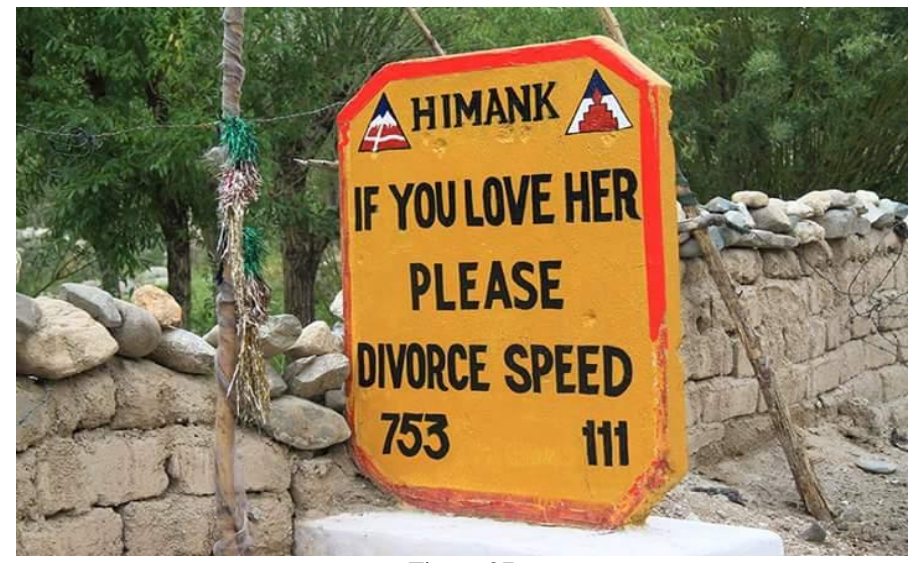

Figure 27 
The caution on the sign post reads: "if you love her, please divorce speed". Again the warning is drawn up on a square shaped sign post with yellow backgrounds and red borders. This notice is put up to caution the drivers from over speeding on the highways. This cautionary notice is most likely drawn up for family men, speaking of husbands, fathers, boyfriends or male drivers in general who have some sort of affiliation with the opposite sex. The notice sensitizes

the male driver to 'divorce speed' i.e. to avoid over speeding if he truly cares about his partner. This cautionary notice appeals to the sense of emotions of the driver, and as such, any driver who must have been approaching with full speed, would have a rethink when he comes across such notice. The notice performs representative acts as it would help the driver reaffirm his matrimonial oaths by avoiding over speeding. Its perlocutionary effect is to help the driver develop an attitudinal change as regardsover speeding.

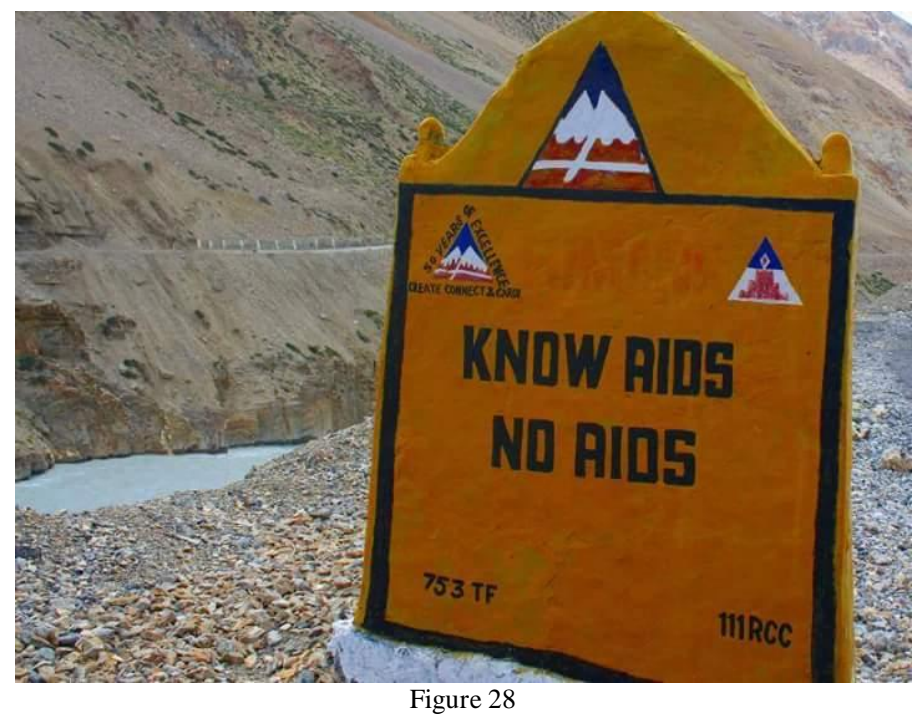

The inscription reads: "KNOW AIDS, NO AIDS". The illocution is that the driver should know the rules on the road and make use of them to prevent theuse of aids or rescue when accident occurs. The caution is that it isbetter for the driver to know the rules and follow them than to get involve in accident that might need people to come to his/her...aid.

The texts above express the writers' attitude about a number of states of affairs. Hence, they are tagged Expressive Act. Besides, they state psychological states or mind set of the writers toward such issues as immodest, unsafe, hurried and rally-like kind of driving. The texts condemn these and cautioned road users against reckless driving. Above this level, the fourth text in this group apology. To submit, all in all, the texts seek to make people to conform to modest, safe, calm and ethical ways of driving.

\section{CONCLUSION}

One could say that in spite of the differences which exist in the presented and examined cautionary notices based on the words with which and the landscape on which they are written, they all purposefully pursue one common goal that is attitudinal change. They are garnished with varied illocutionary acts written with diversified tones which depict affirmation, request, challenge, apology, threats and swear. They attempt to awaken the consciousness of the road users and lessen ghastly occurrences on the high ways. This is the very reason why the notices are said to be functional and critical linguists see them as utterances that perform actions. From the available facts, cautionary notices that are assertive here seek to dissuade people from speeding too much and stay conscious while driving.

One who has closely observed the study would realize that the various items listed from the research indicates a single message which is a warning cum advices. The items expressed several illocutionary acts engraved, written and displayed with tones which depict affirmation, request, challenge, apology and advice. The notices and the content's decision are to sensitize the road users in order to check the excessive road accidents on Nigerian highways. This is evident to the reason why linguists settle more to analyze the effect of the messages intended. Obviously, cautionary notices advice people to stay conscious while using the highways. The data highlighted in the work expresses the angle of communication and its effects on the readers, who are mainly the road users, either pedestrians or drivers.

Some of the texts ask, challenge, command, insist, request, and beg the road users to perform one action or the other. The said texts call for a restrained driving, implore road users to do nothing while driving and go slow to avoid accident. The third category of the data shows the writers' commitment to several degrees of actions. Here, the cautionary notices appeal harsh, with somewhat a tone of threat. The last class of the data expresses the writers' attitude about a number of states of affairs and deplores reckless driving. To submit, all in all, the examined notices seek to make people conform to modest, reserved, safe, calm and ethical ways of driving. The effects of this on the road users are called perlocutionary force. This is the definite consequence of the functional texts as they noticeably result into the declined 
in speed and improved consciousness of the road users. To this end, this paper examines cautionary notices in some details and brings into fore, the perlocutionary effects of the notices.

\section{REFERENCES}

[1] Brown, G. and Yule G. (1998). Discourse analysis. New York. Cambridge University Press, pp. 1 - 16.

[2] Candin, C.N. (1997). 'General editor's preface' in (eds) Gunnarson, B.L.; Linel, P. and Nardberg, B. The construction of professional discourse. London: Longman, IX - XIV.

[3] Crystal, D. (1987). The Cambridge Encyclopedia of Language. Cambridge University Press.Cambridge.

[4] Fairclough, N. (1992). 'Introduction, in (ed) Fairclough, N. Critical Language. Awareness, London: Longman pp. 8, 28.

[5] Fasold, R. (1990). Sociolinguistics of language, Oxford: Blackwell pp. 65.

[6] Fowler, R. (1981). Literature as social discourse: the practice of linguistic criticism, London: Batsford Academic. Pp. 199.

[7] Halliday, M.A.K. \&Hasan, R. (1985). Language, Context and Text: Aspects of Language in a Social-Semiotic Perspective. Victoria: Deakin University Press. Pp. $1-20$.

[8] Hodge, R. \& Kress, G. (1991). Social Semiotics, Cambridge: Polity Press.

[9] Hutchby, I. \&Wooffitt, R. (1998). Conversation Analysis, Cambridge: Policy Press.

[10] Jaworski, A and Coupland, N. (1999). 'Perspectives on Discourse Analysis in (ed.) Jaworski, A. \&Coupland. The Discourse Reader. Routledge, London and New York: Pp. $1-39$.

[11] Olateju, M. (2004). Discourse Analysis: Analysing Discourse in the ESL Classroom (Revised edition). ObafemiAwolowo University Press Ltd. Nigeria.

[12] Stubbs, M. (1983). Discourse Analysis The Sociolinguistic Analysis of Natural Language. Chicago, IL The University of Chicago Press.

[13] Searle, J.R. (1979). Speech Acts: an essay in the philosophy of language. New York: Cambridge University Press.

[14] Widdowson, H.G. (2000). Linguistics. Oxford: Oxford University Press.

[15] Widdowson, H.G. (2007). Discourse Analysis, Oxford: Oxford University Press.

Opoola Bolanle Tajudeen holds $\mathrm{Ph} . \mathrm{D}$ in Applied Linguistics from the University of Calabar Nigeria. He is presently an Associate Professor of Linguistics at the Faculty of Arts Federal University, Oye Ekiti Nigeria. Opoola specializes in Applied Linguistics and had published several books and articles in Linguistics and Language teaching and Learning. He also has many contributions in sociolinguistics and Language study.

Folorunso, Emmanuel Awoniyi teaches Linguistics at Oun state University Osogbo Ikire Campus, Nigeria. Awoniyi holds B A, MA phonology and currently on his Ph.d program specializing in Clinical Linguistics. He has books and Journal article contributions in many reputable Journals.

Opoola Ayobami Fatimo is a Chief Lecturer at the Federal College of Education where she teaches Language education since 1992' Ayobami holds B.A, Linguistics, MA English Language, M.ed. Early Childhood Education and currently on a Ph.d programe sat Lead City University Ibadan, Nigeria. Ayobami has more than four books published in Linguistics and Language study. She is a specialist in Phonetics of Yoruba Langusge.

Olatubosun Odusanya holds B A ed, M. ed at Olabisi Onabanjo University Ago Iwoye and presently on his Ph.d programe at the University of Ibadan Nigeria, He is a specialist in e learning and teaching through open distant learning. He is a product of Idhra Ghandi University of Distance Learning in India where he obtained his Med with lair for Language study. Olatunbosun has several published works on Language teaching through distance learning. 